\title{
Cancer incidence attributable to insufficient fibre consumption in Alberta in 2012
}

\author{
Anne Grundy PhD, Abbey E. Poirier MSc, Farah Khandwala MSc, Alison McFadden BSc, \\ Christine M. Friedenreich PhD, Darren R. Brenner PhD
}

See also www.cmajopen.ca/lookup/doi/10.9778/cmajo.20150068

\section{Abstract}

Background: Insufficient fibre consumption has been associated with a increased risk of colorectal cancer. The purpose of this study was to estimate the proportion and absolute number of cancers in Alberta that could be attributed to insufficient fibre consumption in 2012.

Methods: The number and proportion of colorectal cancers in Alberta attributable to insufficient fibre consumption were estimated using the population attributable risk. Relative risks were obtained from the World Cancer Research Fund's 2011 Continuous Update Project on colorectal cancer, and the prevalence of insufficient fibre consumption $(<23 \mathrm{~g} / \mathrm{d})$ was estimated using dietary data from Alberta's Tomorrow Project. Age- and sex-specific colorectal cancer incidence data for 2012 were obtained from the Alberta Cancer Registry.

Results: Between $66 \%$ and $67 \%$ of men and between $73 \%$ and $78 \%$ of women reported a diet with insufficient fibre consumption. Population attributable risk estimates for colorectal cancer were marginally higher in men, ranging from $6.3 \%$ to $6.8 \%$ across age groups, whereas in women they ranged from $5.0 \%$ to $5.5 \%$. Overall, $6.0 \%$ of colorectal cancers or $0.7 \%$ of all cancers in Alberta in 2012 were estimated to be attributable to insufficient fibre consumption.

Interpretation: Insufficient fibre consumption accounted for $6.0 \%$ of colorectal cancers in Alberta in 2012. Increasing fibre consumption in Alberta has the potential to reduce to the future burden of colorectal cancer in the province.

- n 2012, colorectal cancer was the fourth most common cancer and second most common cause of cancer death in Alberta. ${ }^{1}$ In a follow-up from their 2007 analysis, ${ }^{2}$ the World Cancer Research Fund Continuous Update Project 2011, which focused on colorectal cancer, identified 12 new cohort studies addressing associations with dietary fibre and classified the evidence for fibre consumption as "convincing" for a decreased risk of colorectal cancer. ${ }^{3}$

Although the exact mechanism through which fibre consumption influences colorectal cancer risk is not entirely clear, several plausible biological pathways have been hypothesized and investigated. Specifically, increased fibre consumption is thought to increase fecal bulk, diluting carcinogens and decreasing transit time through the bowel, reducing the opportunity for said carcinogens to interact with the intestinal lumen. ${ }^{4}$ Furthermore, both alterations to bile acid metabolism and the fermentation of fibre by microflora present in the colon, which leads to an increase in apoptosis, are considered potential mechanisms that could link fibre consumption with a decreased risk of colorectal cancer., ${ }^{4,5}$

Previous work has estimated that $12.2 \%$ of colorectal cancers diagnosed in the United Kingdom in 2010 were attributable to insufficient fibre consumption, which translated to a population attributable risk of $1.5 \%$ for all cancers. ${ }^{6}$ Similar work conducted in Australia estimated that up to $18 \%$ of colorectal cancers diagnosed in adults aged 29 years and older in 2010 were attributable to insufficient consumption of dietary

Competing interests: None declared.

This article has been peer reviewed.

Correspondence to: Darren Brenner, darren.brenner@ albertahealthservices.ca

CMAJ Open 2017. DOI:10.9778/cmajo.20160043 
fibre. $^{7}$ The purpose of this study was to estimate the proportion and number of colorectal cancers in Alberta in 2012 that could be attributed to insufficient intake of dietary fibre.

\section{Methods}

This article is the part of a series of exposure-specific articles concerning the proportion of cancer attributable to modifiable lifestyle and environmental risk factors in the general population of Alberta. The methodologic framework for this series has been previously described. ${ }^{8}$ Because they conducted the only existing study of population attributable cancer risk related to dietary fibre published at the time our study began, a similar approach to Parkin and Boyd ${ }^{6}$ was employed to evaluate the population attributable risk of colorectal cancer related to insufficient fibre consumption in Alberta. Parkin and Boyd's methods were used to allow our results to be directly compared with their existing work. Population attributable risks for colon and rectal cancers individually were estimated in addition to all colorectal cancers combined.

\section{Assessment of fibre intake}

Levels of fibre consumption in Alberta were obtained from data from Alberta's Tomorrow Project. ${ }^{9}$ The project is a population-based cohort study conducted in Alberta that included a diet history questionnaire as part of baseline data collection. ${ }^{9}$ Participants in Alberta's Tomorrow Project are volunteers, and the study population is considered to be geographically representative of the province of Alberta. The diet history questionnaire was composed of a cognitive-based foodfrequency questionnaire developed by the United States National Cancer Institute as a tool to assess diet over the preceding 12 months. ${ }^{9}$ Data used in this analysis were collected between 2000 and 2009, where data derived from the diet history questionnaire were used to estimate total dietary fibre intake in grams per day. We used a guideline of $23 \mathrm{~g} / \mathrm{d}$ of fibre intake to evaluate attributable risks related to colorectal cancer in line with previous estimations. ${ }^{6}$ This is within the range of $21-38 \mathrm{~g} / \mathrm{d}$ of both dietary and functional fibre intake recommended for general health by Health Canada. Total dietary fibre intake from Alberta's Tomorrow Project data was divided into deciles using all data and the mean level of consumption; the deficit between this mean and the $23 \mathrm{~g} / \mathrm{d}$ guideline and proportion of the population in each decile were estimated for men and women in 4 age groups (35-44, $45-54,55-64$ and $\geq 65 \mathrm{yr}$ ).

\section{Source of relative risk data}

Relative risks (RRs) that link fibre intake to colorectal cancer, as well as to colon and rectal cancers individually, were obtained from the World Cancer Research Fund Continuous Update Project 2011. ${ }^{3}$ Our existing methodologic framework for our series of population attributable cancer risk analyses identified RRs from international collaborative groups such as the World Cancer Research Fund as the ideal source of RR data for population attributable risk analyses. ${ }^{8}$ The RRs presented by the Continuous Update Project are based on a sys- tematic literature review conducted by a panel of experts coordinated through the World Cancer Research Fund. ${ }^{3}$ Because fibre intake is considered protective for colorectal cancer, the risk associated with a decrease of $1 \mathrm{~g} / \mathrm{d}$ of fibre intake was estimated according to equation 1 :

Equation 1: Risk per gram $=\left[\ln \left(1 / \mathrm{RR}_{x}\right)\right] / x$

where $x$ represents the exposure level in grams per day of the original RR.

\section{Assessment of latency period}

As previously described, ${ }^{8}$ follow-up times from cohort studies in the existing peer-reviewed literature were examined to determine the most appropriate latency period between fibre consumption and the development of colorectal cancer. Specifically, we distinguish between the theoretical latency period (time between start of exposure and cancer diagnosis) and the measured latency period (time between exposure measurements and cancer diagnosis), where we attempted to quantify the measured latency period from high-quality cohort studies and refer to it simply as the latency period. Follow-up times from assessment of fibre consumption at baseline to case ascertainment in published cohort studies ranged from 6 to 20 years. ${ }^{10-12}$ Because detailed information on fibre consumption in Alberta by both sex and age group was only available from the Alberta's Tomorrow Project data, this data source was selected and the mean latency period set at 8 years for data collected between 2000 and 2009.

\section{Statistical analyses}

As in Parkin and Boyd ${ }^{6}$ the excess relative risk (ERR) in each fibre consumption category was estimated using equation 2 :

\section{Equation 2: $\mathrm{ERR}=\exp \left(R_{g} \times G_{x}\right)-1$}

where $R_{g}$ represents the increase in risk associated with a $1 \mathrm{~g}$ decrease in fibre consumption per day and $G_{x}$ represents the deficit in consumption $(<23 \mathrm{~g} / \mathrm{d})$ of fibre within consumption category $x$. Population attributable risks were then estimated using equation 3 :

Equation 3: $\mathrm{PAR}=\left[\left(p_{1} \times \mathrm{ERR}_{1}\right)+\left(p_{2} \times \mathrm{ERR}_{2}\right)+\ldots \ldots+\left(p_{x}\right.\right.$ $\left.\left.\times \mathrm{ERR}_{x}\right)\right] /\left\{1+\left[\left(p_{1} \times \mathrm{ERR}_{1}\right)+\left(p_{2} \mathrm{x} \times \mathrm{ERR}_{2}\right)+\ldots \ldots+\left(p_{x} \times\right.\right.\right.$ $\left.\left.\left.\mathrm{ERR}_{x}\right)\right]\right\}$

where $p_{x}$ represents the proportion of the population in consumption category $x$ and $\mathrm{ERR}_{x}$ is the excess relative risk for consumption category $x$. To estimate the total number of cancers attributable to insufficient fibre consumption at each site overall, as well as by age-group and sex, population attributable risks were applied to cancer incidence data obtained from the Alberta Cancer Registry for 2012. The total proportion of cancer attributable to insufficient fibre intake at each cancer site was estimated as the total number of excess attributable cases across age groups divided by the total number of observed cancers at an individual cancer site. 
Monte Carlo methods were used to construct 95\% confidence intervals (CIs) around population attributable risk point estimates. ${ }^{13}$ Prevalence and risk estimates and their associated CIs were used to parameterize a probability distribution from which 10000 random samples were drawn. A binomial probability distribution was assumed for the prevalence of exposure, a $\log$ normal distribution for risk and a Poisson distribution for cancer incidence. The $95 \%$ CIs were then determined by the 2.5th and 97.5th percentiles of the distribution of simulated population attributable risk and excess attributable case estimates. Similar techniques were used by 2 previous studies that estimated population attributable risk. ${ }^{13,14}$ All analyses were conducted in RStudio (version 0.98.1080).

\section{Results}

Total dietary fibre intake by sex and age group is shown in Table 1. A greater proportion of women $(73.5 \%-78.2 \%$ across age groups) than men $(66.2 \%-67.3 \%$ across age groups) in Alberta's Tomorrow Project cohort consumed less than $23 \mathrm{~g} / \mathrm{d}$ of fibre, which was classified as insufficient (Figure 1). The proportions of respondents with insufficient fibre intake were similar across age groups for both men and women and consistently higher for women than men. However, women had lower overall caloric intake compared with men (1640 kcal v. $2237 \mathrm{kcal})$, which may partially explain the lower levels of fibre consumption.

Risks associated with adequate fibre intake for colorectal, colon and rectal cancers used in the estimation of population attributable risks are shown in Table 2. To estimate the population attributable risk of cancer due to inadequate intake, the inverse of the RR estimates in Table 2 were used.

Population attributable risks and $95 \%$ CIs around these population attributable risk estimates for colorectal, as well as colon and rectal cancers separately, are shown in Table 3. These values represent the proportions of cancers that can be attributed to insufficient dietary fibre consumption in Alberta. Because the RRs of colorectal and colon cancers associated

Table 1: Fibre consumption in grams per day and the proportion of the population in each of 10 consumption categories, by age and sex

\begin{tabular}{|c|c|c|c|c|c|c|c|c|c|c|c|c|}
\hline \multirow[b]{3}{*}{$\begin{array}{l}\text { Fibre consumption } \\
\text { category, g/d }\end{array}$} & \multicolumn{12}{|c|}{ Age, yr } \\
\hline & \multicolumn{3}{|c|}{$35-44$} & \multicolumn{3}{|c|}{$45-54$} & \multicolumn{3}{|c|}{$55-64$} & \multicolumn{3}{|c|}{$\geq 65$} \\
\hline & $\begin{array}{l}\text { Grams } \\
\text { per day, } \\
\text { mean }\end{array}$ & $\begin{array}{c}\text { Deficit } \\
\text { from } 23 \\
\text { g/d }\end{array}$ & $\%$ & $\begin{array}{l}\text { Grams } \\
\text { per day, } \\
\text { mean }\end{array}$ & $\begin{array}{l}\text { Deficit } \\
\text { from } 23 \\
\text { g/d }\end{array}$ & $\%$ & $\begin{array}{l}\text { Grams } \\
\text { per day, } \\
\text { mean }\end{array}$ & $\begin{array}{c}\text { Deficit } \\
\text { from } 23 \\
\mathrm{~g} / \mathrm{d}\end{array}$ & $\%$ & $\begin{array}{l}\text { Grams } \\
\text { per day, } \\
\text { mean }\end{array}$ & $\begin{array}{l}\text { Deficit } \\
\text { from } 23 \\
\mathrm{~g} / \mathrm{d}\end{array}$ & $\%$ \\
\hline \multicolumn{13}{|l|}{ Men } \\
\hline $1:<9.38$ & 7.35 & 15.65 & 6.70 & 7.29 & 15.71 & 7.83 & 7.28 & 15.72 & 8.08 & 7.49 & 15.51 & 8.04 \\
\hline 2: 9.38-11.84 & 10.69 & 12.31 & 8.03 & 10.66 & 12.34 & 8.11 & 10.77 & 12.23 & 9.57 & 10.46 & 12.54 & 8.47 \\
\hline 3: 11.85-13.89 & 12.85 & 10.15 & 8.85 & 12.83 & 10.17 & 8.67 & 12.84 & 10.16 & 9.10 & 12.91 & 10.09 & 9.43 \\
\hline 4: 13.90-15.73 & 14.83 & 8.17 & 9.02 & 14.82 & 8.18 & 9.72 & 14.91 & 8.09 & 9.02 & 14.78 & 8.22 & 7.93 \\
\hline 5: 15.74-17.63 & 16.68 & 6.32 & 9.05 & 16.74 & 6.26 & 10.28 & 16.67 & 6.33 & 9.18 & 16.67 & 6.33 & 8.90 \\
\hline 6: 17.64-19.75 & 18.63 & 4.36 & 10.59 & 18.63 & 4.37 & 9.55 & 18.67 & 4.33 & 9.37 & 18.69 & 4.31 & 10.72 \\
\hline 7: 19.76-22.17 & 20.87 & 2.13 & 10.59 & 20.92 & 2.08 & 10.48 & 20.94 & 2.06 & 10.04 & 20.93 & 2.07 & 10.18 \\
\hline 8: 22.18-25.47 & 23.71 & 0 & 11.21 & 23.74 & 0 & 10.56 & 23.79 & 0 & 11.14 & 23.61 & 0 & 10.61 \\
\hline 9: 25.48-30.68 & 27.77 & 0 & 11.62 & 27.80 & 0 & 11.74 & 27.90 & 0 & 11.73 & 27.84 & 0 & 14.15 \\
\hline $10: \geq 30.69$ & 40.10 & 0 & 14.35 & 38.97 & 0 & 13.07 & 38.22 & 0 & 12.78 & 38.98 & 0 & 11.58 \\
\hline Mean & 21.14 & & & 20.54 & & & 20.32 & & & 20.45 & & \\
\hline \multicolumn{13}{|l|}{ Women } \\
\hline $1:<9.38$ & 7.29 & 15.71 & 12.11 & 7.08 & 15.92 & 11.32 & 7.19 & 15.81 & 11.12 & 7.17 & 15.83 & 10.57 \\
\hline 2: 9.38-11.84 & 10.66 & 12.34 & 11.30 & 10.70 & 12.30 & 11.56 & 10.66 & 12.34 & 9.60 & 10.70 & 12.30 & 10.32 \\
\hline 3: 11.85-13.89 & 12.94 & 10.06 & 11.77 & 12.89 & 10.11 & 10.71 & 12.92 & 10.08 & 9.65 & 13.01 & 9.99 & 9.88 \\
\hline 4: 13.90-15.73 & 14.82 & 8.18 & 11.18 & 14.82 & 8.18 & 10.59 & 14.82 & 8.18 & 9.79 & 14.83 & 8.17 & 10.01 \\
\hline 5: 15.74-17.63 & 16.66 & 6.34 & 9.97 & 16.69 & 6.31 & 10.38 & 16.62 & 6.38 & 10.47 & 16.69 & 6.31 & 10.25 \\
\hline 6: 17.64-19.75 & 18.72 & 4.28 & 9.93 & 18.68 & 4.31 & 9.95 & 18.70 & 4.30 & 9.43 & 18.74 & 4.26 & 12.00 \\
\hline 7: 19.76-22.17 & 20.87 & 2.13 & 9.27 & 20.95 & 2.05 & 9.41 & 20.97 & 2.03 & 10.13 & 20.88 & 2.12 & 12.24 \\
\hline 8: 22.18-25.47 & 23.72 & 0 & 8.87 & 23.70 & 0 & 9.42 & 23.73 & 0 & 10.81 & 23.86 & 0 & 7.96 \\
\hline 9: 25.48-30.68 & 27.75 & 0 & 8.50 & 27.74 & 0 & 8.64 & 27.73 & 0 & 9.69 & 27.73 & 0 & 8.76 \\
\hline $10: \geq 30.69$ & 39.03 & 0 & 7.11 & 38.62 & 0 & 8.02 & 37.99 & 0 & 9.31 & 37.88 & 0 & 8.02 \\
\hline Mean & 17.96 & & & 18.28 & & & 18.94 & & & 18.51 & & \\
\hline
\end{tabular}


with insufficient fibre consumption are higher for men than women (Table 2), population attributable risks for colorectal cancer were slightly higher in men $(6.3 \%-6.7 \%, 6-25$ cases) than in women $(5.0 \%-5.5 \%, 4-18$ cases), despite the greater proportion of women who reported insufficient dietary fibre consumption (Table 3). A similar pattern was also observed for colon cancer $(7.4 \%-8.0 \%$ or $3-20$ cases in men, $3.7 \%-$ $4.1 \%$ or $2-10$ cases in women). However, for rectal cancer, where the RRs for men and women are much more similar, the estimated population attributable risks were marginally higher among women $(5.6 \%-6.2 \%$ or $2-5$ cases) than among men $(5.2 \%-5.6 \%$ or $3-7$ cases $)$, which more closely matches

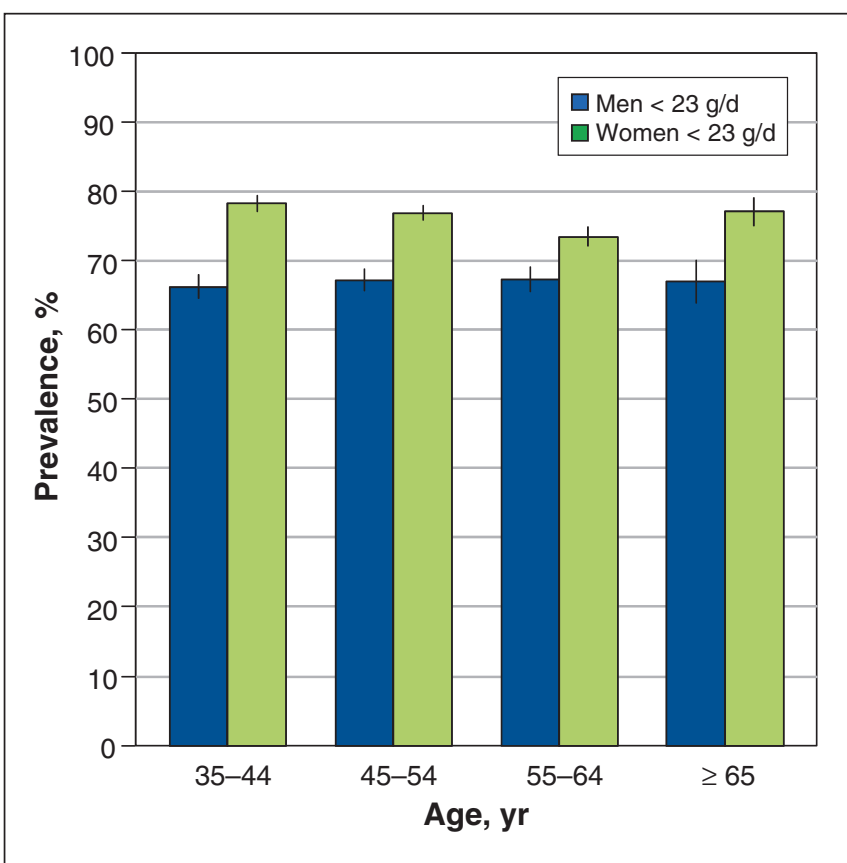

Figure 1: Proportion of men and women in Alberta with insufficient fibre intake $(<23 \mathrm{~g} / \mathrm{d})$ by age group. the differences between men and women in the prevalence of insufficient dietary fibre consumption (Table 3). Among men and women combined, an estimated $6.0 \%$ of colorectal cancers, or $0.7 \%$ of all cancers, diagnosed in Alberta in 2012 were attributable to insufficient fibre intake (Table 4). Out of 1899 cases of colorectal cancer diagnosed in Alberta in 2012, these estimates translated to an excess 114 cases of colorectal cancer (about 71 in men, 42 in women, Table 4).

\section{Interpretation}

About $0.7 \%$ of all cancer cases diagnosed in Alberta in 2012 were estimated to be attributable to insufficient fibre consumption. When considering colorectal cancer specifically, we estimated that about $6.0 \%$ of colorectal cancers in Alberta could be attributed to low dietary fibre intake. These estimates translate to about 114 excess cases of colorectal cancer, with an estimated 71 excess cases in men and 42 excess cases in women.

Our estimate of the proportion of cancers attributable to insufficient fibre consumption is lower than a comparable estimate produced by Parkin and Boyd, where $1.5 \%$ of cancers diagnosed in the UK in 2010 were attributable to low fibre intake. ${ }^{6}$ Our estimates are also lower than those of Nagle and colleagues ${ }^{7}$ for colorectal cancer in Australia in 2010. There are several important methodologic differences that should be considered when comparing the results from the UK and Australia to ours. First, both the UK and Australian analyses used data from population-based surveys that included data from people aged 19 years and older to estimate fibre consumption. ${ }^{6,7}$ In comparison, the data from Alberta's Tomorrow Project only included people aged $35-70$ years. In the UK data, fibre consumption levels were lower in the younger age groups, ${ }^{6}$ and the exclusion of the younger component of the adult population in our analyses could partially explain the lower population attributable risk estimates. In

Table 2: Estimated risks associated with decreased fibre consumption and latency periods for estimation of population attributable risk

\begin{tabular}{|c|c|c|c|c|c|c|}
\hline Cancer site & Sex & RR estimate* & $\begin{array}{l}\text { Units } \\
\text { g/d }\end{array}$ & $\begin{array}{c}\text { Risk per } \\
\text { decrease of } 1 \\
\text { g/d fibre intake }\end{array}$ & Source & $\begin{array}{c}\text { Latency period, } \\
\mathrm{yr}\end{array}$ \\
\hline \multirow[t]{3}{*}{ Colorectal } & All & 0.90 & 10 & 0.011 & WCRF $2011^{3}$ & 8 \\
\hline & Men & 0.88 & 10 & 0.013 & WCRF $2011^{3}$ & 8 \\
\hline & Women & 0.92 & 10 & 0.0083 & WCRF $2011^{3}$ & 8 \\
\hline \multirow[t]{3}{*}{ Colon } & All & 0.89 & 10 & 0.012 & WCRF $2011^{3}$ & 8 \\
\hline & Men & 0.86 & 10 & 0.015 & WCRF $2011^{3}$ & 8 \\
\hline & Women & 0.94 & 10 & 0.0062 & WCRF $2011^{3}$ & 8 \\
\hline \multirow[t]{3}{*}{ Rectum } & All & 0.91 & 10 & 0.0094 & WCRF $2011^{3}$ & 8 \\
\hline & Men & 0.90 & 10 & 0.011 & WCRF $2011^{3}$ & 8 \\
\hline & Women & 0.91 & 10 & 0.0094 & WCRF $2011^{3}$ & 8 \\
\hline
\end{tabular}


addition, different estimates of relative risk were used for the UK and Australian analyses compared with ours. ${ }^{6}$ When converted to risk per decrease of $1 \mathrm{~g} / \mathrm{d}$ of fibre intake, the RR used by Parkin and Boyd was 0.029, whereas the comparable estimate from the World Cancer Research Fund Continuous Update Project was $0.011 .^{3}$ In the Australian analyses, Nagle

Table 3: Cancer cases and proportions attributable to insufficient fibre intake in Alberta, 2012

\begin{tabular}{|c|c|c|c|c|c|c|c|c|c|c|}
\hline \multirow[b]{2}{*}{$\begin{array}{l}\text { Age at } \\
\text { exposure, } \\
y r\end{array}$} & \multirow[b]{2}{*}{$\begin{array}{c}\text { Age at } \\
\text { outcome, yr }\end{array}$} & \multicolumn{3}{|c|}{ Colorectal } & \multicolumn{3}{|c|}{ Colon } & \multicolumn{3}{|c|}{ Rectum } \\
\hline & & $\begin{array}{c}\text { Total } \\
\text { observed } \\
\text { cases }^{*}\end{array}$ & $\begin{array}{c}\text { PAR \% } \\
(95 \% \mathrm{CI}) \dagger\end{array}$ & EAC $\ddagger$ & $\begin{array}{c}\text { Total } \\
\text { observed } \\
\text { cases }^{*}\end{array}$ & $\begin{array}{c}\text { PAR \% } \\
(95 \% \mathrm{Cl}) \dagger\end{array}$ & EAC $\ddagger$ & $\begin{array}{c}\text { Total } \\
\text { observed } \\
\text { cases }^{*}\end{array}$ & $\begin{array}{c}\text { PAR \% } \\
(95 \% \mathrm{Cl}) \dagger\end{array}$ & EAC‡ \\
\hline \multicolumn{11}{|l|}{ Men } \\
\hline $35-44$ & $43-52$ & 96 & $6.3(0.1-7.1)$ & 6 & 38 & $7.4(0.7-7.8)$ & 3 & 58 & $5.2(0-12.2)$ & 3 \\
\hline $45-54$ & $53-62$ & 280 & $6.6(0.2-8.1)$ & 19 & 139 & $7.8(0.9-9.1)$ & 11 & 141 & $5.5(0-13.9)$ & 8 \\
\hline $55-64$ & $63-72$ & 320 & $6.7(0.3-8.6)$ & 22 & 177 & $8.0(0.9-9.4)$ & 14 & 143 & $5.6(0-14.3)$ & 8 \\
\hline$\geq 65$ & $\geq 73$ & 383 & $6.6(0.2-8.5)$ & 25 & 260 & $7.8(0.9-9.3)$ & 20 & 123 & $5.4(0-14.1)$ & 7 \\
\hline Total & & 1079 & & 71 & 614 & & 48 & 465 & & 25 \\
\hline \multicolumn{11}{|l|}{ Women } \\
\hline $35-44$ & $43-52$ & 81 & $5.5(1.2-7.5)$ & 4 & 42 & $4.1(0-10.8)$ & 2 & 39 & $6.2(0-14.6)$ & 2 \\
\hline $45-54$ & $53-62$ & 181 & $5.3(1.1-7.1)$ & 10 & 105 & $4.0(0-10.4)$ & 4 & 76 & $6.0(0-14.3)$ & 5 \\
\hline $55-64$ & $63-72$ & 202 & $5.0(1.0-6.3)$ & 10 & 125 & $3.7(0-9.1)$ & 5 & 77 & $5.6(0-12.3)$ & 4 \\
\hline$\geq 65$ & $\geq 73$ & 356 & $5.1(1.1-6.9)$ & 18 & 265 & $3.8(0-9.7)$ & 10 & 91 & $5.8(0-13.5)$ & 5 \\
\hline Total & & 820 & & 42 & 537 & & 21 & 283 & & 17 \\
\hline \multicolumn{11}{|l|}{ Total } \\
\hline $35-44$ & $43-52$ & 177 & 5.9 & 11 & 80 & 5.7 & 5 & 97 & 5.6 & 5 \\
\hline $45-54$ & $53-62$ & 461 & 6.1 & 28 & 244 & 6.2 & 15 & 217 & 5.7 & 12 \\
\hline $55-64$ & $63-72$ & 522 & 6.1 & 32 & 302 & 6.2 & 19 & 220 & 5.6 & 12 \\
\hline$\geq 65$ & $\geq 73$ & 739 & 5.9 & 43 & 525 & 5.8 & 30 & 214 & 5.6 & 12 \\
\hline Total & & 1899 & & 114 & 1151 & & 68 & 748 & & 42 \\
\hline
\end{tabular}

Table 4: Summary of cases and proportions of cancer in Alberta in 2012 attributable to insufficient fibre consumption

\begin{tabular}{|c|c|c|c|c|c|c|c|c|c|}
\hline \multirow[b]{2}{*}{ Cancer site } & \multicolumn{3}{|c|}{ Total } & \multicolumn{3}{|c|}{ Men } & \multicolumn{3}{|c|}{ Women } \\
\hline & $\begin{array}{l}\text { Observed } \\
\text { cases }^{*}\end{array}$ & $\begin{array}{l}\text { Excess } \\
\text { attributable } \\
\text { cases† }\end{array}$ & $\begin{array}{c}\% \\
\text { Attributable }\end{array}$ & $\begin{array}{l}\text { Observed } \\
\text { cases }^{*}\end{array}$ & $\begin{array}{l}\text { Excess } \\
\text { attributable } \\
\text { cases† }\end{array}$ & $\begin{array}{c}\% \\
\text { Attributableł }\end{array}$ & $\begin{array}{l}\text { Observed } \\
\text { cases* }^{*}\end{array}$ & $\begin{array}{c}\text { Excess } \\
\text { attributable } \\
\text { cases } \dagger\end{array}$ & $\begin{array}{c}\% \\
\text { Attributable }\end{array}$ \\
\hline Colorectum & 1899 & 114 & 6.0 & 1079 & 71 & 6.6 & 820 & 42 & 5.2 \\
\hline Colon & 1151 & 68 & 6.0 & 614 & 48 & 7.8 & 537 & 21 & 3.8 \\
\hline Rectum & 748 & 42 & 5.6 & 465 & 25 & 5.4 & 283 & 17 & 5.9 \\
\hline $\begin{array}{l}\text { All } \\
\text { associated } \\
\text { cancers§ }\end{array}$ & 1899 & 114 & 6.0 & 1079 & 71 & 6.6 & 820 & 42 & 5.2 \\
\hline All cancers & 15836 & 114 & 0.7 & 8155 & 71 & 0.9 & 7681 & 42 & 0.5 \\
\hline \multicolumn{10}{|c|}{$\begin{array}{l}\text { *Represents total number of incident cancer cases in } 2012 \text { from the Alberta Cancer Registry. } \\
\text { †Number of cancer cases at individual cancer sites that can be attributed to insufficient fibre consumption. } \\
\text { †Proportion of cancers at individual cancer sites attributable to insufficient fibre consumption. Estimated as excess attributable cases/observed cases. } \\
\text { §Represents all cancers with a known association with insufficient fibre consumption, as listed in table. Here this represents colorectal cancer, as colon and rectal cancers } \\
\text { are subsets of this. } \\
\text { १Represents all incident cancers in Alberta in } 2012 \text { in all age groups. }\end{array}$} \\
\hline
\end{tabular}


and colleagues conducted a sensitivity analysis using the World Cancer Research Fund RRs used in our analysis, which produced estimates for Australia (6.0\% of colorectal cancer cases, $0.8 \%$ of all cancer cases) very similar to those for Alberta. ${ }^{7}$ Thus, differences between the estimates of RR across studies likely explains a large portion of the observed difference in population attributable risks between the Alberta results and those in the main analyses for both Australia and the UK.

\section{Limitations}

Because information on the prevalence of insufficient fibre consumption was taken from Alberta's Tomorrow Project, the ability of this cohort to accurately represent fibre consumption in the Alberta population needs to be considered. Specifically, because the cohort is composed of volunteers, although it is geographically representative of the population of Alberta, the potential for volunteer bias and systematic differences in dietary patterns between participants and nonparticipants is possible.

Data on mean fibre consumption in Alberta were available from the Canadian Community Health Survey Cycle 2.2 (Nutrition) conducted in 2004, where equivalent values from Alberta's Tomorrow Project cohort and the 2004 Canadian Community Health Survey showed that means for comparable age groups were consistently lower in Canadian Community Health Survey data. ${ }^{15}$ Consequently, Alberta's Tomorrow Project data may somewhat overestimate fibre consumption, leading to an underestimation of the proportion of colorectal cancers attributable to insufficient consumption. Furthermore, the use of Alberta's Tomorrow Project data to estimate fibre consumption levels meant that the longer latency periods suggested by large cohort studies between fibre consumption and colorectal cancer incidence could not be explored. ${ }^{10-12}$ For this reason, if a longer latency period represented a more biologically relevant window for exposure, and fibre consumption levels in Alberta in the more distant past were higher or lower than those captured among cohort members, estimates of population attributable risk could have been either over- or underestimated.

A strength of this analysis was the use of Monte Carlo methods that incorporated variation associated with estimates of RR and exposure prevalence to produce 95\% CIs to quantify the precision of population attributable risk estimates. However, these CIs are relatively wide and indicate that although we estimate an excess 114 cases of colorectal cancer in Alberta due to insufficient fibre consumption, the true number could be as low as 11 or as high as 146 . Thus, this lack of precision in our population attributable risk estimates needs to be considered when interpreting the results of our analysis.

\section{Conclusion}

We estimate that about $6.0 \%$ of colorectal cancers or $0.7 \%$ of all cancers in Alberta in 2012 can be attributed to insufficient consumption of fibre. Although the individual population attributable risks associated with fibre intake are relatively small $(<10 \%)$, because colorectal cancer is the second most common cancer in Alberta, just under 1\% of all cancers in the province can be considered attributable to low fibre intake. Future studies that incorporate a measure of fibre consumption that covers a greater age range than that captured by the data from Alberta's Tomorrow Project will provide important context for our findings. Additional research that provides estimates of population attributable risk related to fibre consumption from other regions of Canada will highlight how the potential burden of colorectal cancer related to fibre in Alberta fits in the broader Canadian context. Finally, fibre consumption is a modifiable exposure and thus represents a strong target for continued cancer prevention initiatives.

\section{References}

1. Shack L. 2012 report on cancer statistics in Alberta: Cancer in Alberta. Edmonton: CancerControl AB, Alberta Health Services; 2015.

2. Food, nutrition, physical activity, and the prevention of cancer: a global perspective. Washington (DC): World Cancer Research Fund/American Institute for Cancer Research; 2007.

3. Continuous update project report. food, nutrition, physical activity, and prevention of colorectal cancer. Washington (DC): World Cancer Research Fund/American Institute for Cancer Research; 2011.

4. Young G, Hu Y, Le Leu R, et al. Dietary fibre and colorectal cancer: a model for environment-gene interactions. Mol Nutr Food Res 2005;49:571-84.

5. Dahm C, Keogh R, Spencer E, et al. Dietary fiber and colorectal cancer risk: a nested case-control study using food diaries. F Natl Cancer Inst 2010;102:614-26.

6. Parkin D, Boyd L. 6. Cancers attributable to dietary factors in the UK in 2010. Br 7 Cancer 2011;105(Suppl 2):S27-30.

7. Nagle CM, Wilson LF, Hughes MCB, et al. Cancers in Australia in 2010 attributable to inadequate consumption of fruit, non-starchy vegetables and dietary fibre. Aust N Z 7 Public Health 2015;39:422-8.

8. Grundy A, Friedenreich CM, Poirier AE, et al. A methodologic framework to evaluate the number of cancers attributable to lifestyle and environment in Alberta, Canada. CMA7 Open 2016;4:E471-78

9. Bryant H, Robson PJ, Ullman R, et al. Population-based cohort development in Alberta, Canada: a feasiblity study. Chronic Dis Can 2006;27:51-9.

10. Park Y, Hunter DJ, Spiegelman D, et al. Dietary fiber intake and risk of colorectal cancer. FAMA 2005;294:2849-57.

11. Murphy N, Norat T, Ferrari P, et al. Dietary fibre intake and risks of cancers of the colon and rectum in the European prospective investigation into cancer and nutrition (EPIC). PLoS One 2012;7:e39361.

12. Hansen L, Skeie G, Landberg R, et al. Intake of dietary fiber, especially from cereal foods, is associated with lower incidence of colon cancer in the HELGA cohort. Int 7 Cancer 2012;131:469-78.

13. Renehan AG, Soerjomataram I, Tyson M, et al. Incident cancer burden attributable to excess body mass index in 30 European countries. Int 7 Cancer 2010;126:692-702.

14. Lee I-M, Shiroma EJ, Lobelo F, et al. Effect of physical inactivity on major noncommunicable diseases worldwide: an analysis of burden of disease and life expectancy. Lancet 2012;380:219-29.

15. Canadian Community Health Survey, cycle 2.2, Nutrition (2004): a guide to assessing and interpreting the data [Nutrient intakes from food: provincial, regional and national summary data tables, volume 1]. Ottawa: Health Canada; 2004.

Contributors: Christine Friedenreich and Darren Brenner were responsible for the study conception. Anne Grundy, Christine Friedenreich, Darren Brenner, Farah Khandwala and Abbey Poirier contributed substantially to the study design and interpretation of the data. Farah Khandwala completed the analysis. Alison McFadden and Anne Grundy were responsible for acquisition of the data Abbey Poirier, Anne Grundy, Christine Friedenreich, Farah Khandwala, Alison McFadden and Darren Brenner prepared the manuscript, gave final approval of this version to be published and agreed to be guarantors of the work.

Affiliations: Department of Cancer Epidemiology and Prevention Research (Grundy, Poirier, Khandwala, McFadden, Friedenreich, Brenner), CancerControl Alberta, Alberta Health Services; Department of Oncology, Cumming School of Medicine (Friedenreich, Brenner), University of Calgary; Department of Community Health Sciences (Friedenreich, Brenner), Cumming School of Medicine, University of Calgary, Calgary, Alta.

Acknowledgements: This project was funded by the Alberta Cancer Prevention Legacy Fund. Dr Christine Friedenreich is supported by an Alberta Inno- 
vates-Health Solutions Health Senior Scholar Award and the Alberta Cancer Foundation Weekend to End Women's Cancers Breast Cancer Chair at the University of Calgary. Dr. Darren Brenner is supported by a Capacity Development Award in Prevention from the Canadian Cancer Society Research Institute (703917). The authors thank Dr. Laura McDougall from the Alberta Cancer Prevention Legacy Fund for her support and guidance. The authors also thank Bethany Kaposhi and Lorraine Shack from the Alberta Cancer Registry for providing cancer incidence data, the department of Data Integration, Measurement and Reporting at Alberta Health Services for access to CCHS data and Eileen Shaw for critical review of this manuscript. The authors are grateful for the prevalence data from the Alberta's Tomorrow
Project. Alberta's Tomorrow Project is only possible due to the commitment of its research participants, its staff and its funders: Alberta Cancer Foundation, Canadian Partnership Against Cancer, Alberta Cancer Prevention Legacy Fund (administered by Alberta Innovates - Health Solutions) and substantial in kind funding from Alberta Health Services. The views expressed herein represent the views of the author(s) and not of Alberta's Tomorrow Project or any of its funders.

Supplemental information: For reviewer comments and the original submission of this manuscript, please see www.cmajopen.ca/content/5/1/ E7/suppl/DC1 